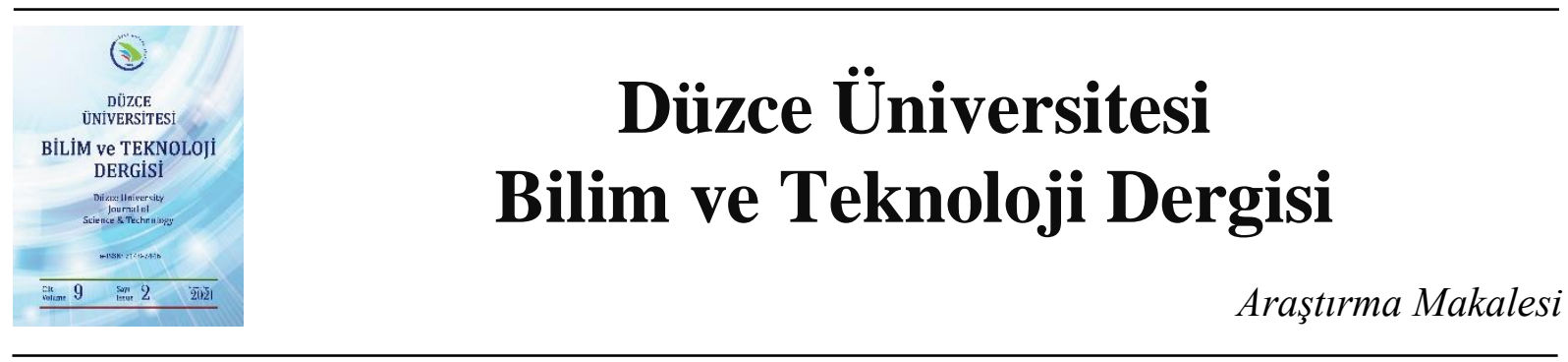

\section{Yeşil Bir Villanın Tasarım Maliyetinin Klasik Villa Tasarım Maliyetiyle Karşılaştırılması}

\author{
Melike YALILI KILIÇ a, , (D) Sümeyye ADALI ${ }^{\text {a }}$ \\ ${ }^{a}$ Çevre Mühendisliği Bölümü, Mühendislik Fakültesi, Bursa Uludă̆ Üniversitesi, Bursa, TÜRKIYE \\ * Sorumlu yazarın e-posta adresi: myalili@uludag.edu.tr
}

DOI: $10.29130 /$ dubited.820515

\begin{abstract}
ÖZET
Günümüzde gelişmişlik düzeyinin artışıyla beraber enerji arzında meydana gelen değişim, yenilenebilir enerji kaynaklarının kullanımını gündeme getirmiștir. Hem güvenli hem de tükenmez olan bu kaynaklar, konutların enerji ihtiyacını karşılama noktasında da birçok avantaja sahiptir. Bu çalışmada, Bursa'da şehrin yerel iklim koşullarına uygun olarak tasarlanmış yeşil bir villanın yenilenebilir enerji kurulum maliyeti ile amortisman süresi hesaplanmış ve klasik villa olma durumunda oluşacak maliyetlerle kıyaslaması yapılmıştır. Yeşil villa ile klasik villanın enerji sarfiyatları incelendiğinde, yeşil villada 2047,24 €/yıl tasarruf sağlandığı; yeşil villanın yenilenebilir enerji yatırım maliyetinin 11 yıl 3 ay gibi bir sürede kendini amorti edebileceği belirlenmiştir.
\end{abstract}

Anahtar Kelimeler: Amortisman süresi, Maliyet, Yenilenebilir Enerji, Yeşil Villa, Bursa

\section{Comparison of the Design Cost of a Green Villa with the Cost of a Classic Villa Design}

\begin{abstract}
The change in energy supply has brought the use of renewable energy resources to the agenda with the increase in development level today. These resources, which are both safe and inexhaustible, have many advantages in meeting the energy needs of residences. In this study, the renewable energy installation cost and the depreciation period of a green villa designed in accordance with the local climatic conditions of Bursa were calculated and compared with the costs that would occur in case of a classic villa. When the energy consumption of the green villa and the classic villa is examined, it is seen that $2047.24 € /$ year is saved in the green villa; it has been determined that the renewable energy investment cost of the green villa can pay off in 11 years and 3 months.
\end{abstract}

Keywords: Depreciation period, Cost, Renewable Energy, Green Villa, Bursa 


\section{GIRIS}

Dünya genelindeki nüfus artışı, sanayi ve teknolojik gelişmeler ve bunlara paralel olarak artan ham madde ve enerji ihtiyacı, özellikle doğada yenilenemeyen kaynakların aşırı düzeyde tüketilmesine yol açmıştır. Bu durum tüm dünyayı enerji kaynaklarının tükenme tehlikesiyle, Orta Doğu'da yer alan zengin yer altı kaynaklarına sahip ülkeleri ise enerji güvenliği problemiyle karşı karşıya bırakmıştır. Enerji kaynakları arasında önemli yer tutan fosil yakıtlara olan bağımlılığın azaltılması ve çevreye verdiği zararların en az düzeye indirilmesi amacıyla alternatif enerji kaynaklarının kullanımı günümüzde gittikçe yaygınlaşarak önem kazanmaktadır.

Dünyadaki enerji kaynaklarının yaklaşık yarısı konutlarda tüketilmekte olup nüfusa bağlı olarak konut sayısının artışıyla beraber bu oran giderek yükselmektedir. Çoğu fosil tabanlı olan bu kaynakların kullanımı hava ve su kirliliği başta olmak üzere çevre ve insan sağlığı üzerinde birçok probleme neden olmaktadır. Fosil yakıtlara alternatif olarak hem çevreci hem de doğada tükenmez olması nedeniyle tarım, sanayi ve hizmet alanında yer alan birçok sektörde yenilenebilir nitelikteki kaynakların kullanımı yükselen bir eğilimdedir [1]. Bu sektörlerden birisi olan konut sektörü, yeşil bina anlayışıyla enerji ve kaynak tasarrufunun sağlanması ve çevresel sürdürülebilirliğin gerçekleşmesini amaçlayarak çalışmalarını sürdürmektedir [2]. Yeşil bina, doğaya ve bulunduğu yörenin koşullarına uygun olarak tasarlanmış, enerjisini yenilenebilir özellikteki kaynaklardan sağlayan, minimum atık üretimini amaçlayan sürdürülebilir nitelikteki yapıları ifade etmektedir [3]. Yeşil binalarda yenilenebilir özellikteki enerji türleri arasında güneş enerjisi ve rüzgâr enerjisi kullanımı ilk sıralardadır. Bu enerji türlerinin yanında biyokütle enerjisi, jeotermal enerji ve hidroelektrik enerjiden de belirli oranlarda yararlanılmaktadır [4]. Bu tür yapılarda enerji tüketiminde \%24-50, $\mathrm{CO}_{2}$ emisyonunda \%33-39, su tüketiminde \%40, oluşan atık miktarlarında \%70'e varan azalım sağlanacağı belirtilmektedir [3].

Yeşil bina kriterlerinin belirlenmesi ve bu tür yapıların değerlendirilmesini sağlamak amacıyla oluşturulan ulusal ve uluslararası özelliğe sahip birçok sertifikasyon sistemi mevcuttur. Oluşturulacak olan yapıya uygun sistemin seçimi hem inşa aşamasında hem de daha sonraki süreçte ergonomik ve ekonomik yönden katkı sağlamaktadır [5,6]. Dünya genelinde yaygın olarak kullanılan yeşil bina sertifikasyon sistemleri arasinda Building Research Establishment-Environmental Assessment Method (BREEAM), Leadership in Energy and Environmental Design (LEED), Comprehensive Assessment System for Built Environment Efficiency (CASBEE), Green Star, Deuthche Gesellschaft für Nachhaltige Bauen (DGNB) v.b. yer almaktadır [7]. BREEAM İngiltere'de 1990 yılında ortaya konmuş ilk kapsamlı yapı değerlendirme yöntemi olup Kanada, Avustralya, Hong Kong ve birçok ülkede yaygın olarak kullanılmaktadır [8]. BREEAM yöntemi, farklı kategoriler altında yeşil bina değerlendirmesini amaçlamakta, bu kategoriler arasında yönetim, sağlı ve refah, enerji, ulaşım, su, malzeme, atık, kirlilik, inovasyon, arazi kullanımı ve ekoloji yer almaktadır [9]. Amerika'da oluşturulmuş ve benimsenmiş olan LEED sertifikasyon sistemi ise, ülkemizde ve dünya genelinde en çok tercih edilen sistemdir $[9,10]$. Amerika'da yeşil binalar için bir standart olarak kabul edilen bu sistemde sürdürülebilir alanlar, su verimliliği, enerji ve atmosfer, malzeme ve kaynak, iç mekan kalitesi, lokasyon ve ulaşım, inovasyon ve bölgesel öncelik kategorilerinde değerlendirme gerçekleştirilmektedir [9, 11].

Sertifika sistemlerinde farklı kullanım amaçlarına göre inşa edilmiş binalara uygun değerlendirme yapabilmek amacıyla sınıflandırma yoluna gidilmektedir. Sınıflandırma binanın durum ve tipolojisine göre yapılmaktadır. Durum sınıflandırması "mevcut, yeni, geçici, renovasyon ve bakım-onarım" başlıkları altında değerlendirilmektedir [10]. Başlıca sertifika sistemleri ve uygulandıkları bina tipolojileri Tablo 1'de verilmiştir. 
Tablo 1. Başlıca Sertifikasyon Sistemleri ve Uygulandıkları Bina Tipolojileri [10].

\begin{tabular}{|c|c|c|c|c|c|c|c|c|c|c|c|c|c|c|c|c|c|c|c|c|c|}
\hline \multirow{2}{*}{$\begin{array}{l}\text { Sertifikasyon } \\
\text { Sistemi } \\
\end{array}$} & \multicolumn{21}{|c|}{ Uygulandığı Bina Tipolojileri } \\
\hline & 1 & 2 & 3 & 4 & 5 & 6 & 7 & 8 & 9 & 10 & 11 & 12 & 13 & 14 & 15 & 16 & 17 & 18 & 19 & 20 & 21 \\
\hline BREEAM & + & + & + & + & + & + & + & + & + & & & & & & & & & & & & \\
\hline CASBEE & & & & & + & + & & & + & & + & + & & & & & & & & & \\
\hline LEED & & + & & & + & & & & + & & & + & & + & & & & & & & \\
\hline GREEN STAR & & + & & + & + & + & + & & + & & & & & & & & & & & & \\
\hline DGNB & & & & + & + & + & + & & + & & & & + & & + & + & + & + & + & + & + \\
\hline $\begin{array}{l}\text { 1. Mahkeme bi } \\
\text { 6.Ticari binal } \\
\text { ve kentsel ge } \\
\text { Laboratuvarlo } \\
\text { alanlart }\end{array}$ & isim & nd & & & $\begin{array}{l}\text { ina } \\
\text { bina } \\
\text { vb.) } \\
\text { ari }\end{array}$ & arl & 3. $\mathrm{Il}$ & & & $\begin{array}{l}m b \\
l e r\end{array}$ & $K c$ & itla & $\begin{array}{l}\bar{g} \bar{g} l i \\
10 .\end{array}$ & $\begin{array}{l}\text { bin } \\
\text { Cap }\end{array}$ & $\begin{array}{l}\text { rdeg } \\
\text { eri } 2\end{array}$ & $\begin{array}{l}\text { Of } \\
\text { ark } \\
15 \\
\text {. } S\end{array}$ & $\begin{array}{r}\text { bir } \\
\text { ar } 1 \\
\text { Kc } \\
\text { or } k\end{array}$ & $\begin{array}{l}\text { larl } \\
\text { Isl } \\
\text { gre } \\
\text { mple }\end{array}$ & $\begin{array}{l}\text { e ia } \\
\text { dalc }\end{array}$ & $\begin{array}{l}\text { ri bi } \\
12 .\end{array}$ & $\begin{array}{r}\text { alar } \\
\text { Kent } \\
16 . \\
\text { Hava }\end{array}$ \\
\hline
\end{tabular}

Ülkemizde bu sistemler örnek alınarak oluş̧urulmuş iki sertifika sistemi mevcuttur. Bunlardan biri Çevre Dostu Yeşil Binalar Derneği (ÇEDBİK) tarafindan oluşturulan, Çevre ve Şehircilik Bakanlığ tarafindan desteklenen Binalarda Ekolojik ve Sürdürülebilir Tasarım Konut Sertifikası (B.E.S.T) [12], bir diğeri Mimar Sinan Güzel Sanatlar Üniversitesi bünyesinde oluşturulmuş Sürdürülebilir Enerji Etkin Binalar (SEEB-TR)'dır. Her iki sistem de ülkemiz şartlarına uygunluk göz önüne alınarak meydana getirilmiştir. Ulusal sertifika niteliğindeki B.E.S.T., ülkemizde sürdürülebilir yapı anlayışıyla gerçekleştirilecek çalışmalara ana kılavuz olma niteliğindedir [13].

Yeşil binalar geleneksel olarak oluşturulmuş binalara göre daha üstün bir teknoloji ve AR-GE çalışmas1 gerektirmektedir. Bu durum yeşil binaların tasarım ve inşa aşamasında maliyetini arttırırken, kullanım aşamasında sağladığı tasarruflar nedeniyle kurulum masraflarını belirli bir zaman içinde amorti etmektedir. Tablo 2'de yeşil yapı örneklerinin maliyet ve tasarruf analizini ele alan çalışmalar yer almaktadir.

Tablo 2. Yeşil yapı örneklerinin maliyet ve tasarruf analizini ele alan çalışmalar

\begin{tabular}{ccc}
\hline Yapı Türü & Analiz Türü & Çalışma Yürütücüleri \\
\hline Yeşil konut & Enerji ve inşa maliyeti & Bayar ve Atılgan [14] \\
\hline Yeşil ofis & Enerji ve inşa maliyeti & Yalılı Kılıç ve Yahşi [15] \\
\hline Yeşil okul/kampüs & Enerji maliyeti & Kayın [16] \\
\hline Yeşil otel & Madde ve enerji tasarrufu & Mesci [17] \\
\hline Yeşil alışveriş merkezi & Enerji tasarrufu & Şenol [18] \\
\hline
\end{tabular}

$\mathrm{Bu}$ çalışmada enerjisini yenilenebilir kaynaklardan sağlayabilecek yeşil bir villa tasarımı yapılmış ve tasarlanan villanın ilk yatırım maliyeti hesaplanmıştır. İlave olarak, bu villanın geleneksel olarak tasarlanması durumunda oluşan maliyet farklılığ 1 , yeşil villada kullanılan yenilenebilir enerji sistemlerinin sağladığ 1 tasarruf ile sistemlerin amortisman süresi de belirlenmiştir.

\section{TÜRKIYY VE DÜNYADAN YEȘIL YAPI ÖRNEKLERI}

Dünya genelinde yeşil bina anlayışıyla inşa edilmiş birçok yapı örneği mevcuttur. Bunlardan biri, Amerika'da yer alan Idea House projesidir (Şekil 1.a). LEED sertifikasına sahip olan bu çiftlik evinde erozyonu önlemek amacıyla saman balyalarından yararlanılmıştır. Bölgede tercih edilen bitkilerin suya dayanıklı olmasına özen gösterilmiştir. Çatısında bulunan yağmur suyu toplama sistemi sayesinde biriken suyun tuvaletlerde kullanımı gerçekleştirilerek su tasarrufu sağlanmaktadır. Bu yapı, yeşil 
olmayan bir yapıya göre enerjiyi $\% 43$, suyu ise $\% 80$ oranında daha verimli kullanmaktadır $[19,20]$. İsveç'in Malmö şehrinde yer alan bir konut projesi olan Salongen 35'in yapımında kullanılan malzemeler tamamen çevre dostu olup, yeşil çatıya sahip olan yapılarda A sınıfı enerji ve su tasarrufu gerçekleştirilmektedir (Şekil 1.b). Almanya'da yer alan STADTHAUS M1 yeşil konut projesinde ise, bölgenin iklim şartları dolayısıyla 1sı yalıtımlı dış cephe kaplamalarıyla hava sıcaklığının sıfırın altında $15^{\circ}$ ’lere düştüğü bölgede yüksek 1sı verimliliği sağlanmaktadır [21].

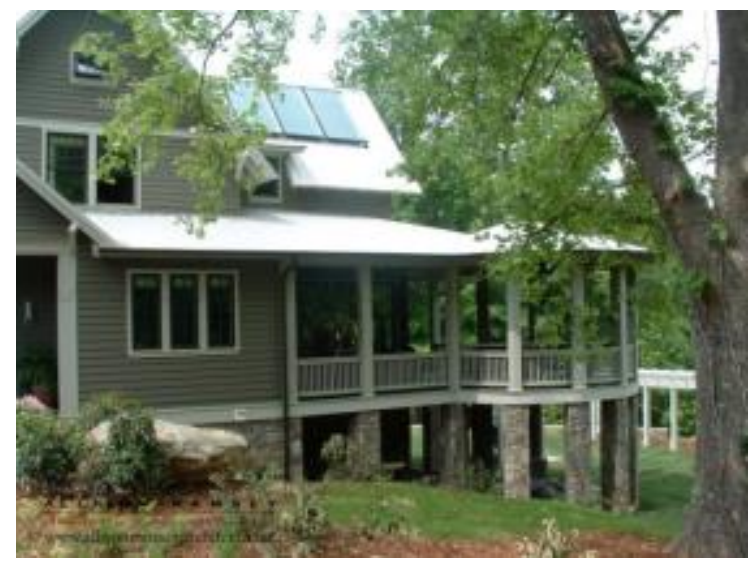

(a)

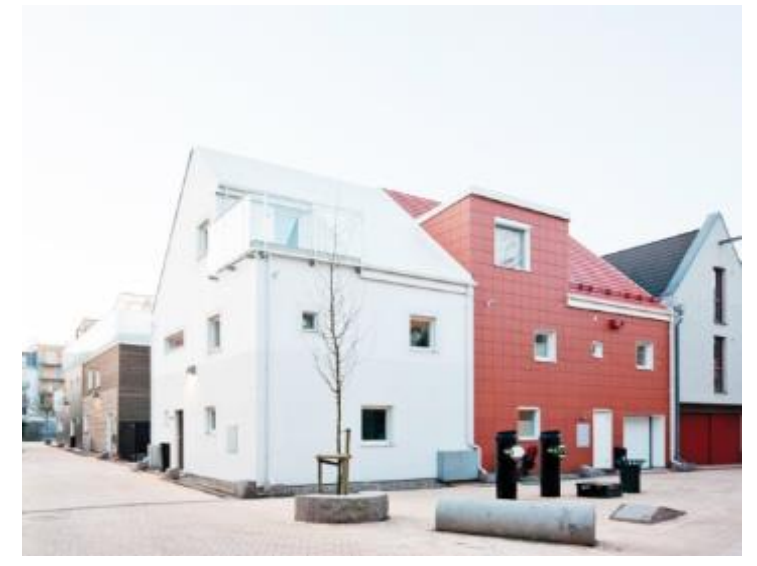

(b)

Şekil 1. (a) Idea House ve (b) Salongen 35 Konut Projeleri

İskoçya'da bulunan Acharacle İlkokulunun elektrik ihtiyac1 rüzgar tribününden elde edilmekte, tuvaletlerde yağmur suyu kullanılmaktadır (Şekil 2.a). Aydınlatmalar gün ışı̆̆ına göre ayarlanarak tasarruf edilmekte, ısınma ihtiyacının bir kısmı bilgisayarların enerjisiyle sağlanmaktadır [22]. Amerika'nın San Francisco kentinde bulunan Hotel Bardessono, LEED Platin sertifikasına sahiptir (Şekil 2.b). Enerji kaynaklarının kullanımı diğer otellerle kıyaslandığında \%50 oranında daha azdır. Otelde gün ışı̆̆ından maksimum ölçüde faydalanılmakta, güneş kırıcıların açısı otomatik olarak değişmektedir. Sıcak su temini yer altı sularından sağlanmaktadır. Güneş enerjisi kullanımı maksimum ölçüde gerçekleştirilmektedir. Aydınlatmada halojen ve floresan lambalar tercih edilerek enerji tasarrufu sağlanmaktadır. Plastik kullanımı minimum seviyede tutulmuş olup otelde kullanılan halı, kilim ve mobilya kumaşları yeşil sertifikaya sahiptir. İnşaat malzemelerinin \%95'i geri dönüşümlü malzemelerden seçilmiştir [23, 24].

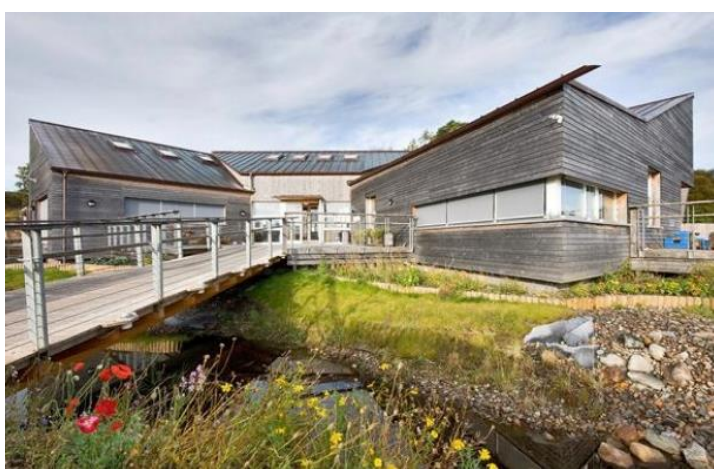

(a)

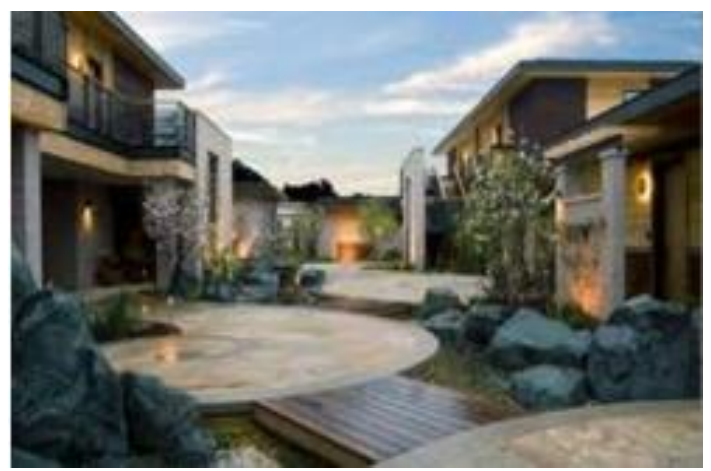

(b)

Şekil 2. (a) Acharacle Illkokulu ve (b) Hotel Berdessono

İngiltere'de yer alan BREEM sertifikasına sahip olan Edge Lane Hastanesinde, oluşan 1sı kayıplarını ve $\mathrm{CO}_{2}$ emisyonlarını azaltmak için yüksek kalitede yalıtım sağlanmıştır. Isı geri kazanımlı mekanik havalandırma sistemine sahip olan hastanede gaz yakıtla çalışan birleşik 1S1 ve güç kaynağı mevcuttur $[25,26]$. 
AB ülkeleri, Japonya, Çin, Hindistan, Brezilya ve Kuzey Amerika'da yeşil bina sektöründe yıllık 150 milyar dolarlık yüksek yatırım potansiyelinin mevcut olduğu bildirilmektedir [27].

Ülkemizde İstanbul Beylerbeyi semtinde ÇEDBİK Konut Sertifikası doğrultusunda yapılmış, 88 konutun bulunduğu Antteras projesiyle (Şekil 3.a), yapım aşamasında meydana gelebilecek çevresel etkiler azaltılmış, projede arazi konumunun ulaşım ağlarına yakın seçilmesi sağlanarak $\mathrm{CO}_{2}$ emisyonunun azaltılması amaçlanmıştır. Rezervuarlarında gri su kullanımına olanak vermesi, tasarımının güneş ışığından en yüksek faydayı sağlayacak şekilde oluşturulması ve yapılarda enerji verimliliği yüksek olan cihazların tercih edilmesi sayesinde su ve enerji tasarrufu sağlanmaktadır [28]. Bunun dışında ülkemizde birçok yeşil konut projesi yer almakta olup, bunlar arasında Diyarbakır ve Muğla gibi güneşlenme süresinin fazla olduğu şehirlerde bulunan sıfır enerji tüketimini amaçlayan Güneş Evleri, yenilenebilir enerji sistemlerinin kullanımıyla fosil yakıt kullanımı ve kaynak tüketiminin azaltılmasını amaçlayan konut ve konut dışı projeler yer almaktadır [18].

Schneider Electric firmasının Manisa'da bulunan binası, Türkiye'de in-use kategorisi BREEAM /Mükemmel Yeşil Bina Sertifikası almaya hak kazanan ilk fabrika binasıdır. Fabrika, kendi üretimi olan güneş enerji sistemiyle, ihtiyacı olan enerjinin bir kısmını yenilenebilir özellikteki kaynaktan sağlamayı amaçlamakta, çatılarda bulunan açıklıklar sayesinde ise güneş ışıllarından daha fazla miktarda faydalanmaktadır. Enerji kaybının önlenmesi amacıyla fabrikada çeşitli faaliyetler sonucu harcanan enerji miktarları izlenmekte ve kaydedilmektedir. Yağmur suları depo edilerek peyzaj sulamasında kullanılmaktadır. Uygulanan yöntemler sayesinde enerjiden $\% 28$, sudan $\% 57$ oranında tasarruf sağlanan fabrikada kaynak verimliliği \%45 civarında elde edilmiştir [29].

İstanbul'da yer alan LEED Gold sertifikasına sahip olan Hilton Garden Inn İstanbul Golden Horn Hotel, sıcak su ihtiyacını 6 ay boyunca güneş panellerinden elde edilen enerjiyle sağlamaktadır. İnşaatında kullanılan malzemelerinin \%30’u geri dönüştürülmüş malzeme özelliğindedir. Binada elde edilen tasarruf yıllık \%70 civarındadır [23, 30].

Ülkemizin ilk büyük ekolojik karma projesi olan Varyap Meridian, içerisinde konut, otel, ofis ve alışveriş merkezi gibi birçok yapıyı barındırmaktadır. LEED kriterlerinin sağlandığı projede atık maliyetlerinde \%50-90, $\mathrm{CO}_{2}$ salınımında \%35 oranında azaltımın gerçekleşmekte olduğu, su tasarrufunun ise $\% 30$ oranında sağlandığı bildirilmektedir [31].

Çevreci bir anlayışla inșa edilen İstanbul Havalimanı terminal binası, LEED altın sertifikasına sahip en büyük bina olma özelliğini taşımaktadır (Şekil 3.b). İnşaat sırasında yerel ve geri dönüştürülmüş malzemeler kullanılmıştır. Havalimanında az su tüketen batarya ve rezervuarlar tercih edilmiştir. Rezervuarlarda gri su kullanımına olanak sağlanmaktadır. Peyzaj sulama amacıyla arıtılmış atıksudan faydalanılarak su tüketimde \%100 tasarruf elde edilmektedir. Dış cephe tasarımı, mekanik ekipman ve aydınlatma sistemleri seçiminde enerji verimliliği göz önünde bulundurulmuştur. Sistemlerde kullanılan enerji, her bir sistem için ayrı olarak belirlenmekte ve izlenmektedir [32].

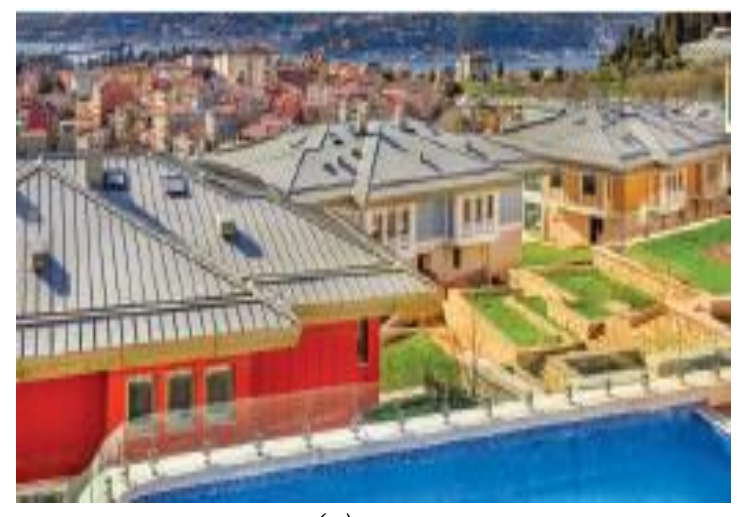

(a)

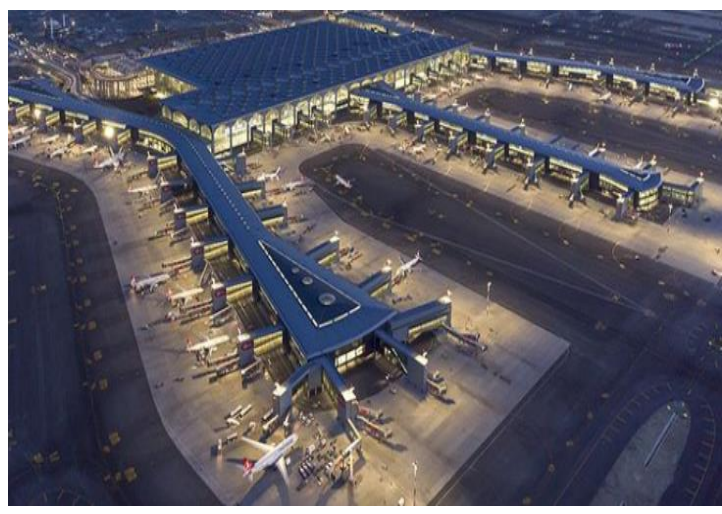

(b)

Şekil 3. (a) Antteras konutları ve (b) İstanbul Havalimanı Terminal Binası 
Yeşil ofis uygulaması kapsamında İstanbul' da yer alan Avea Maçka binası, sürdürülebilirlik anlayışıyla yeniden düzenlenerek LEED Gold sertifikası almıştır. Bu kapsamda yenilenebilir enerji kaynaklarından biri olan rüzgar enerjisi kullanılarak hem karbon salınımı hem de enerji talebi düşürülmüştür. Su ve aydınlatma armatürleri tasarruflu olanlar ile değiştirilmiş, lambaların içerisindeki cıva oranları belirlenmiştir. Gri suyun arıtılarak depolanması sağlanmış ve peyzaj sulamasında kullanılmıştır [33].

Ülkemizde son yıllarda trend olan yeşil bina anlayışı, yapı sektöründe önemli bir yer bulmuş; 2019 Nisan ayı itibariyle sertifikaya sahip yeșil bina sayısı 400'e yükselmiş ve bunun sonucunda Avrupa ülkeleri arasında birinci sırayı almıştır [34].

\section{MATERYAL VE METOT}

Bu çalışmada Bursa ili Osmangazi ilçesine bağlı Kükürtlü mahallesinde bulunan kentsel dönüşüm alanı olan bir arsa üzerine 2020 yılında şehrin iklim şartlarına uygun olarak tasarlanmış, yeşil alana sahip, yenilenebilir enerji kaynaklarından faydalanılabilen yeşil bir villanın enerji maliyetleri ve yapılan enerji yatırımın amortisman süresi hesaplanmıştır. Hesaplanan bu maliyet, klasik bir villanın enerji maliyetleri ile karşılaştırılarak yeşil villanın sağlayabileceği imkanlarla elde edilebilecek ekonomik tasarruf miktarı belirlenmeye çalışılmıştır.

Toplamda $300 \mathrm{~m}^{2}$ 'lik bir alanda villa olarak tasarlanacak olan konutun birinci katında $28,5 \mathrm{~m}^{2}$ oturma odası, $30 \mathrm{~m}^{2}$ mutfak, $12 \mathrm{~m}^{2}$ hol, $5 \mathrm{~m}^{2}$ banyo-WC ve $69 \mathrm{~m}^{2}$ salon bulunmaktadır. Villanın ikinci katında ise 30 'ar $\mathrm{m}^{2}$ 'den iki adet oda, 25 'şer $\mathrm{m}^{2}$ 'den iki adet oda ve $32 \mathrm{~m}^{2}$ hol bulunmaktadır.

Yeşil villada klasik villaya ek olarak elektrik ihtiyacını karşılayacak güneş panellerine ve elektrik tasarrufu sağlayacak aydınlatma cihazlarına, ssıtma ve soğutma ihtiyacını karşılayacak toprak kaynaklı 1s1 pompasına ve 1sı alışverişini minimuma indirmek için yalıtım sistemi ile ssı yalıtımlı camlara, sıcak su ihtiyacını karşılayacak boylere, su tüketiminde tasarruf sağlamak amacıyla bahçe sulama ve kullanım suyu kaynağı olması için yağmur suyu depolarına ve tasarruflu armatürlere yer verilmiştir.

İnşa edilecek villanın ön cephesi ana yol istikametine bakacaktır. Mevcut halde arsanın anayolla kot farkı bulunmamaktadır. Fakat arka cephede bulunan cadde ile arsa arasında yüksek bir kot fark1 mevcuttur. Arsanın içerisinde yıkım sonucu oluşan engebeler düzeltilerek villanın düz bir zeminde oluşturulması düşünülmektedir. Şekil 6' da villaya ait plan ve görünüşler yer almaktadır. 


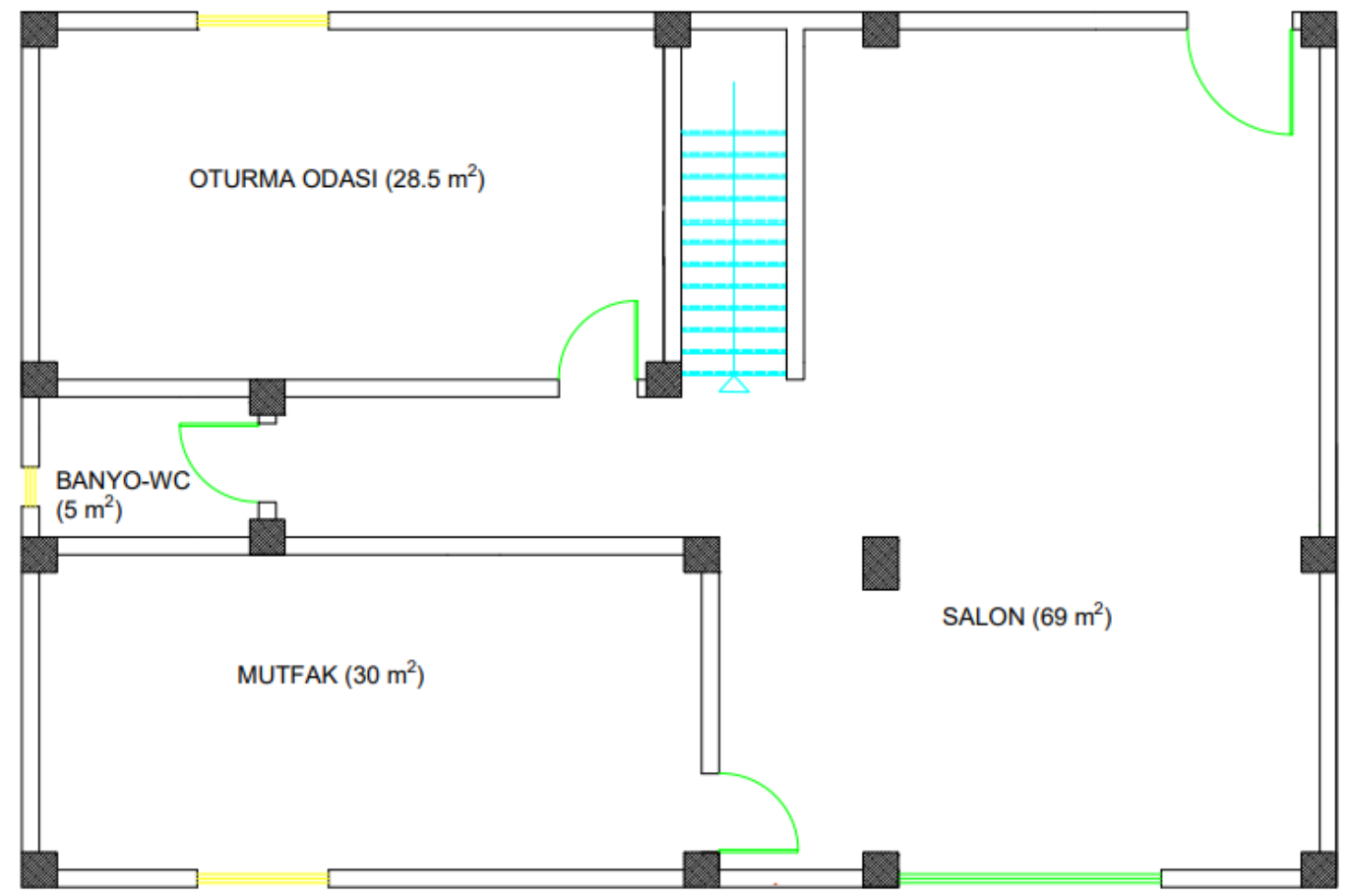

(a)

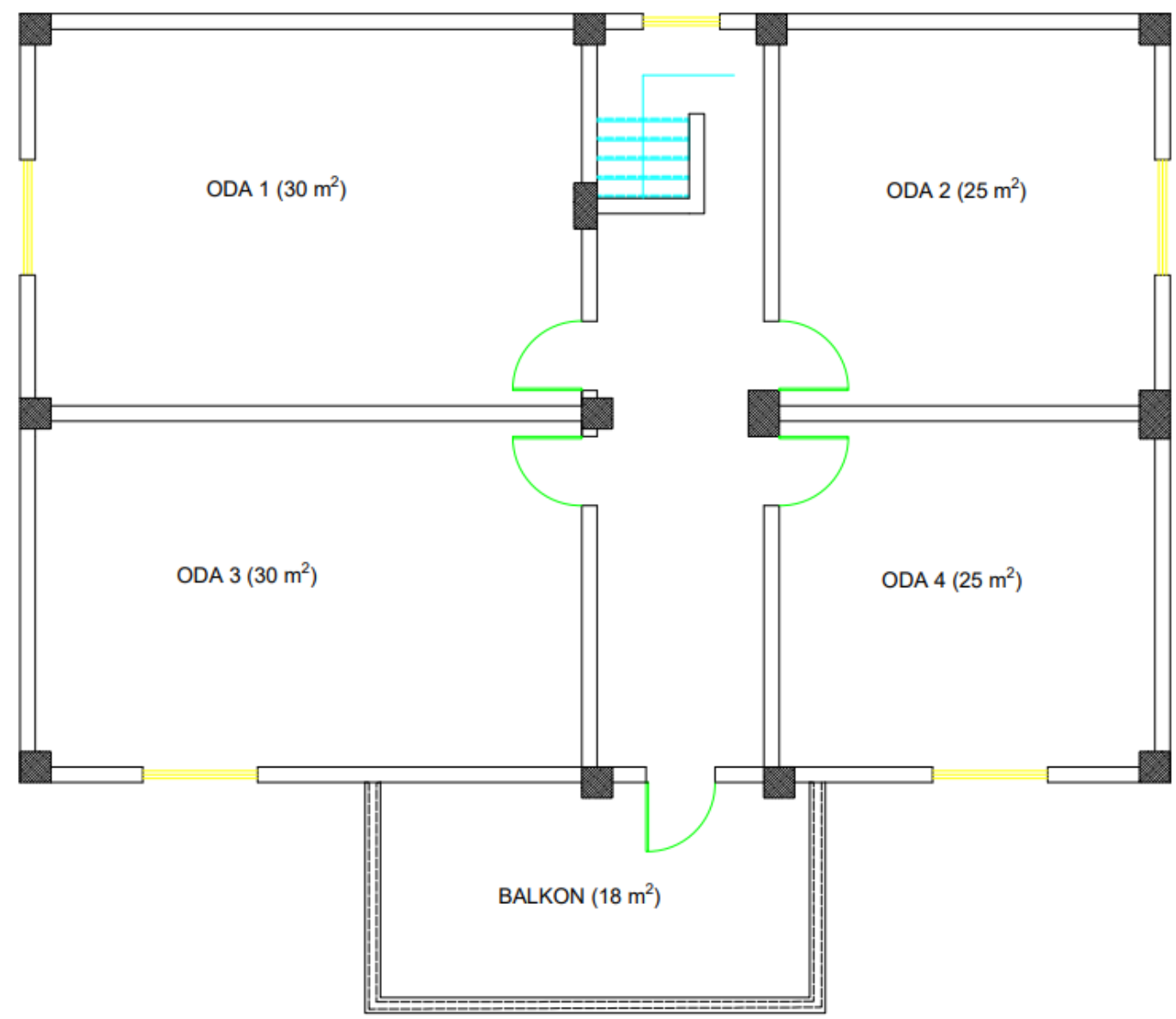

(b)

Şekil 4. Villanin (a) Birinci kat planı ve (b) İkinci kat planı 


\section{BULGULAR VE TARTISMA}

\section{A. KLASIK VİLLA İLE YEŞİL VİLLA İÇIN MALIYYET KARŞILAŞTIRMASI}

Klasik villa ve yeşil villa için yapılan maliyet analizi Tablo 3 'te verilmiştir. Hesaplamada villanın yapım aşamasından başlayarak tüm ana unsurlar ele alınarak maliyetler belirlenmiştir.

Tablo 3. Klasik ve yeşil villanın toplam maliyetlerinin karşılaştırılması

\begin{tabular}{|c|c|c|}
\hline Harcama kalemi & Klasik villa & Yeşil villa \\
\hline Pencere & $732,66 €$ & $732,66 €$ \\
\hline Siva & $3264,24 €$ & $3264,24 €$ \\
\hline Su sistemi & $514,28 €$ & $836,27 €$ \\
\hline Beton & $2943,34 €$ & $2943,34 €$ \\
\hline Demir & $6068,58 €$ & $6068,58 €$ \\
\hline Duvar örme maliyeti & $7539,14 €$ & $7539,14 €$ \\
\hline Harç & $907,26 €$ & $907,26 €$ \\
\hline Kolon & $547,8 €$ & $547,8 €$ \\
\hline Çatı & $4102,96 €$ & $3418,36 €$ \\
\hline Elektrik tesisatı & $692,4 €$ & $714,09 €$ \\
\hline Döşemeler & $1296,54 €$ & $1296,54 €$ \\
\hline Duşakabin & $105 €$ & $105 €$ \\
\hline Kapılar & $495,5 €$ & $495,5 €$ \\
\hline Merdiven & $352,76 €$ & $352,76 €$ \\
\hline Mutfak dolapları & $778,67 €$ & $778,67 €$ \\
\hline Elektrikli ev eşyaları & $2910,93 €$ & $2910,93 €$ \\
\hline Isitma sistemi & $1775,27 €$ & $4411,55 €$ \\
\hline Güneş Paneli maliyeti & - & $13328,8 €$ \\
\hline Is1 pompas1 maliyeti & - & $6412,13 €$ \\
\hline Yalıtım maliyeti & $1893,7 €$ & $1893,7 €$ \\
\hline Yağmur suyu depo maliyeti & - & $1002,83 €$ \\
\hline Toplam maliyet & $36921,03 €$ & $59960,15 €$ \\
\hline
\end{tabular}

$1 €=8,476$ TL (12 Ăgstos 2020 döviz kurları referans alınmıştır.)

\section{B. KLASIK VÍLLA ILE YEŞİL VILLANIN ENERJİ SARFIYATI AÇISINDAN KARŞILAŞTIRMASI}

Yeşil villada yer alan elektronik cihazların sarf ettikleri elektrik enerjisi miktarları Tablo 4 'te verilmiştir. Elektrik tüketim değerleri [35] referans alınarak villada oluşacak yıllık enerji kullanım miktarı hesaplanmıştır.

Tablo 4. Yeșil villadaki temel cihazların bir saatte sarf ettikleri elektrik enerjisi miktarı [35]

\begin{tabular}{ccc}
\hline Cihaz & Sınıf & Enerji Tüketimi $(\boldsymbol{W} / \mathbf{s a})$ \\
\hline Buzdolabı & A+ sınıfi & 40 \\
\hline Çamaşır makinesi & A+ sınıfi & 800 \\
\hline Bulaşık makinesi & A+ sınıfi & 1800 \\
\hline Fırın & - & 2000 \\
\hline Saç kurutma makinesi & - & 2200 \\
\hline Televizyon & - & 180 \\
\hline Ütü & - & 2800 \\
\hline Elektrik süpürgesi & - & 1450 \\
\hline İç aydınlatma & - & 23 \\
\hline Klima & - & 3700 \\
\hline Kombi & - & 150
\end{tabular}

Villanın buzdolabı, aydınlatma, televizyon ve diğer elektrikli ev aletlerinden kaynaklanan elektrik tüketiminin hesaplanmasında, buzdolabının ve kombinin günde 24 saat, televizyonun ise günde 5 saat 
çalıştığı öngörülmüştür. İç aydınlatmada kullanılan 23 adet tasarruflu ampulün aynı anda en fazla 8 adedinin (salonda 6 ve mutfakta 2 adet) kullanılacağı kabul edilmiştir. İç aydınlatma 6 saat kullanılacaktır. İç aydınlatma için; 23 Wsa, beyaz ışıklı, A enerji sınıfı, ekonomi ampulleri seçilmiş olup bu ampuller, klasik 100 Wsa güçteki ampullere eşdeğerdir. \%80 oranında enerji tasarrufu sağlayabilen bu ampuller yeşil villa tasarımı için idealdir. Tasarruflu ampullerin adet fiyatı $0.943 €$ 'dur [36]. Yeşil villanın elektrik tesisatı klasik villa ile aynı olmakla beraber sadece ampuller değiştiğinde elektrik tesisat1 maliyeti;

- $\quad 692,4 €+(23 * 0.943 €) \approx 714,09 €$ 'dir.

Bulaşık makinesi, çamaşır makinesi, elektrikli firın, klima ve ütünün güneşlenme süresi içerisinde çalıştırılacağ1 ve aynı anda çalıştırılmayacağı düşünülmüştür (çamaşır makinesi üzerinden hesap yapılmıştır). Haftalık çalışma günleri, bulaşık makinesi için 3 gün, çamaşır makinesi için 2 gün, ütü için 1 gün, elektrikli firın için 1 gün, elektrik süpürgesi için 1 gün kabul edilerek günlük 2 saat çalışacakları öngörülmüştür.

Elektrikli ev aletlerinin günlük elektrik enerjisi harcaması aşağıdaki şekilde gerçekleşmektedir.

- $(40 * 24)+(180 * 5)+(800 * 2 * 2)+(23 * 8 * 6)+(150 * 24)=9764 \mathrm{Wsa} /$ gün= 3563,86 $\mathrm{kWsa} / \mathrm{y} 1 \mathrm{l}$

Klasik bir villanın bir günlük sarf edeceği elektrik enerjisi miktarı hesaplanırken, sadece kullanılacak aydınlatma ürünleri değişiklik göstermiş olup, diğer elektronik ev aletlerinin hepsi aynı şekilde alınmıştır. İç aydınlatmada 23 adet 100 watt' lık tasarrufsuz ampuller kullanılmıştır. Bu durumda elektrik enerjisi ihtiyac1;

- $\quad(40 * 24)+(180 * 5)+(800 * 2 * 2)+(100 * 8 * 6)+(150 * 24)=13460 \mathrm{Wsa} /$ gün= 4912,9 $\mathrm{kWsa} / \mathrm{y} 1 \mathrm{l}$ olarak hesaplanmıştır.

\section{KLASÍK VILLA İLE YEŞiL VILLANIN SU SARFIYATI AÇISINDAN KARŞILAŞTIRMASI}

Klasik bir villada tasarrufsuz musluklar dakikada 8-27 L tüketmekte, tasarrufsuz rezervuarlar 16 L su depolamakta, tasarrufsuz duş başlıkları $20 \mathrm{~L}$ su akıtmaktadır. Bahçe sulamasında ise evde harcanan suyun \%30' u kullanılmaktadır [37]. Villanın klasik ve yeşil nitelikte olma durumunda oluşacak su tüketim değerleri [37] incelendiğinde;

- $\quad$ Bir kişinin günde banyo ve mutfak musluklarından 10 dakikalık su sarfiyatı sonucu $20 * 10=200$ L tüketim olacaktır (Bir musluk dakikada $20 \mathrm{~L}$ sarfiyat gerçekleştirmektedir). 4 kişilik bir aile için bu değer $200 * 4=800$ L'dir.

- $\quad$ Bir kişi bir günde ortalama 5 kez WC kullanırsa $16 * 5=80$ litre su tüketecektir. 4 kişilik bir aile için bu değer $80^{*} 4=320 \mathrm{~L}$ olacaktır.

Bir kişi günde bir kez olmak üzere 10 dakika duş alırsa $20 * 10=200 \mathrm{~L}$ su tüketecektir. 4 kişilik bir aile için bu değer $200 * 4=800 \mathrm{~L}$ olacaktır.

- CÇamaşır ve bulaşık makineleri su sarfiyatı klasik villa ve yeşil villa için aynı olacağı için hesaplamaya katılmamıştır.

Bu sonuçlara göre klasik bir villada günde ortalama 1920 L su tüketimi gerçekleşmektedir.

Yeşil bir villada ise yukarıda bahsedilen tasarruflu ürünlerin kullanılmasıyla; 
- $\quad$ Dakikada $7 \mathrm{~L}$ su tüketimi yapan tasarruflu musluklar ile $10 \mathrm{dk} * 7 \mathrm{~L} * 4 \mathrm{kişi}=280 \mathrm{~L}$ su tüketimi gerçekleşecektir.

4 L' lik su deposu alanına sahip tasarruflu rezervuar ile 5 defa*4 L*4 kişi=80 L su tüketimi gerçekleşecektir.

- Dakikada 14 L su tüketimi yapan tasarruflu duş başlı̆ğ ile $10 \mathrm{dk} * 14 \mathrm{~L} * 4$ kişi=560 L su tüketimi gerçekleştirecektir.

Bu sonuçlara göre yeşil bir villada bir günde ortalama su tüketimi 920 L olacaktır.

Tablo 5'te klasik villa ile yeşil villanın su sarfiyatı açısından karşılaştırılması verilmektedir. Tabloya göre klasik villada bir yıllık su sarfiyatı $643,64 €$ iken, yeşil villada $277,49 €$ 'dur ( $12 \mathrm{~m}^{3}$ altı su sarfiyat1 $0,46 € / \mathrm{m}^{3} ; 12 \mathrm{~m}^{3}$ üstü su sarfiyatı $0,87 € / \mathrm{m}^{3}$ 'tür) [38].

Tablo 5. Klasik villa ile yeşil villanın su sarfiyatı açısından karşılaşstırılması

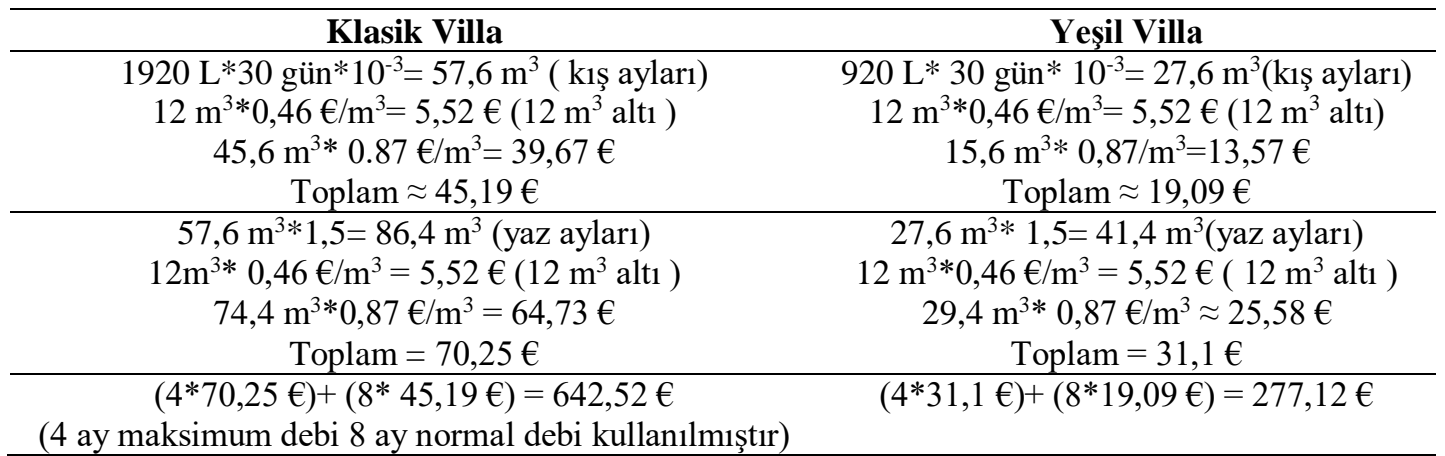

\section{KLASİK VILLA İLE YEŞIL VİLLANIN ELEKTRİK, ISITMA VE SU SARFIYYATLARI AÇISINDAN KARŞILAŞTIRMASI}

Klasik villa ile yeşil villanın elektrik sistemleri, ısıtma sistemleri ve su kullanım sistemleri farklılık göstermektedir. Yapılan 1sı hesapları sonucunda klasik villanın y1llık 1sitma ihtiyac1 69.951,89 kWsa/yıl bulunmuştur. 10,64 kWsa 1sıtma için $1 \mathrm{~m}^{3}$ doğalgaz tüketilmekte olduğundan 1sınma için doğalgaz ihtiyacı $6574,42 \mathrm{~m}^{3}$ olarak hesaplanmıştır. Elektrik kullanım bedeli $0,068 € / \mathrm{kWsa}$ [39]; doğalgaz tüketim bedeli $0,205 € / \mathrm{m}^{3}$ tür [40].

Tablo 6'da klasik villa ile yeşil villanın elektrik, 1sıtma ve su sistemlerinin maliyet farkl111kları verilmiştir. Tabloya göre klasik villanın elektrik, 1sıtma ve su kullanım bedeli y1llık 2324,36€ iken yeşil villada bu bedel $277,12 €$ olarak belirlenmiştir.

Tablo 6. Klasik villa ve yeşil villanın elektrik, ısıtma ve su sistemlerinin yıllık kullanım bedelleri

\begin{tabular}{ccccc} 
& \multicolumn{2}{c}{ Klasik Villa } & \multicolumn{2}{c}{ Yeşil Villa } \\
\cline { 2 - 5 } & Kullanım miktarı & Kullanım bedeli & Kullanım miktarı & Kullanım bedeli \\
\hline Elektrik & $4912,9 \mathrm{kWsa} / \mathrm{y} 1 \mathrm{l}$ & $334,08 € / \mathrm{y} 1 \mathrm{l}$ & $3563,86 \mathrm{kWh} / \mathrm{y} 1 \mathrm{l}$ & - \\
\hline Su & $806,4 \mathrm{~m}^{3} / \mathrm{yl}$ & $642,52 € / \mathrm{y} 1 \mathrm{l}$ & $386,4 \mathrm{~m}^{3} / \mathrm{y} 1 \mathrm{l}$ & $277,12 € / \mathrm{y} 1 \mathrm{l}$ \\
\hline Doğalgaz & $6574,42 \mathrm{~m}^{3} / \mathrm{yll}$ & $1347,76 € / \mathrm{y} 1 \mathrm{l}$ & $1226,56 \mathrm{~m}^{3} / \mathrm{y} 1 \mathrm{l}$ & - \\
\hline Toplam Tutar & & & & $277,12 € / \mathrm{y} 11$ \\
\hline
\end{tabular}




\section{E. AMORTISMAN SÜRESİ}

Yeşil villa ile klasik villa arasındaki maliyet farkının enerji için harcanan tutarların farkına bölümü amortisman süresini verecektir. Yeşil villanın maliyeti 59960,15 €; klasik villanın maliyeti 36921,03 $€$ 'dur. Yeşil villa enerjisi için harcanan y1llık tutar 277,12 €; klasik villa enerjisi için harcanan tutar $2324,36 €$ 'dur.

Yeşil villa ile klasik villa arasındaki maliyet fark1;

- $\quad 59960,15 €-36921,03 €=23039,12 €$ 'dur.

Yeşil villa ile klasik villanın enerji harcamaları arasındaki fark;

- $\quad 2324,36 € / y 11-277,12 € / y 11=2047,24 € / y 11$ 'dır.

Amortisman süresi;

- $23039,12 € / 2047,24 € / y_{11}=11$ y1l 3 ay'dir.

Bu çalışmaya benzer olarak Ankara'da betonarme olarak tasarlanan $100 \mathrm{~m}^{2}$ kullanım alanına sahip iki katlı müstakil bir konutun enerji ihtiyacının yenilenebilir özellikteki kaynaklardan karşılanabilmesi amacıyla yeşil enerji sistemleri incelenmiş ve mevcut konuta uygulanabilirliği araştırılmıştır [14]. Elektrik üretiminin şebekeye bağl1 foltovoltaik panellerden, 1sıtma-soğutma ihtiyacinın 1sı pompası ve güneş kollektöründen, kullanım suyunun ise yağmur suyu depolama sisteminden sağlanması öngörülmüştür. Yenilenebilir enerji sistemlerinin maliyet analizi gerçekleştirilmiş ve toplam kurulum maliyeti 75920 TL olarak bulunmuştur. Isı pompası ve güneş kollektörünün amortisman süresi 8,19 yıl, fotovoltaik panellerin amortisman süresi 7,13 yıl olarak belirtilmiştir.

\section{V.SONUC}

$\mathrm{Bu}$ çalışmada dünyada ve ülkemizdeki çevreci anlayışıla tasarlanmış yeşil bina örnekleri ve sağladıkları faydalar ele alınmış; Bursa ili sınırları içerisinde klasik bir villa tasarımı yapılarak, villanın yeşil yap1 özelliğine sahip olması durumunda yapılacak enerji yatırımlarının amortisman süresi hesaplanmıştır. Yapılan detaylı hesaplamalar neticesinde, klasik villanın maliyeti 36921,03 €, yeşil villanın maliyeti ise 59960,15 € olarak bulunmuştur. Yeşil villa için oluşturulacak ek sistemlerin kurulum maliyeti 23039,12€ olarak hesaplanmış; bu maliyetin 11 yıl 3 ay gibi bir sürede kendini amorti edebileceği belirlenmiştir.

Yeşil binaların sağladığı faydalar arasında;

- Yapılardan kaynaklanan karbon ayak izinin azaltılması,

- Bina yapım aşamasında çevresel tahribatın minimuma indirgenmesi,

- İşletme giderlerinin azaltılmas1,

- Yenilenebilir çevre teknolojilerinin kullanımı ve geliştirilmesi,

- Hafriyat atıklarının değerlendirilmesi,

- Yağmur suyunun biriktirilerek kullanımının sağlanması,

- Güneş ışı̆̆ından maksimum ölçüde faydalanılması,

- Kentsel çevre kalitesinin artması,

- Enerji verimliliğinin sağlanmas1,

- Daha sağlıklı ve ergonomik yaşam alanlarının oluşturulması yer almaktadır [41].

Bu çalışmada, yeşil bina ile geleneksel bina yapımı arasında inşaat maliyeti açısından yüksek bir fark olmadığı, iki bina tipi arasındaki en önemli farkın enerji tüketim maliyetlerinin azaltımı noktasında 
oluşacağı belirlenmiştir. Benzer olarak, yeşil ve geleneksel binalarda maliyetin inşa aşamasında birbirine yakın değerlerde olduğu, binalarda en önemli mali faydanın sağlanan enerji tasarrufu ile ortaya çıkacağ 1 bildirilmektedir $[42,43]$.

Yeşil bina tasarımında kullanılacak olan teknolojilerin kurulum aşamasında önemli bir maliyet kalemi oluşturmasına karşın, uzun vadede sağladığı kaynak tasarrufu düşünüldüğünde hem dünya üzerinde oluşan enerji baskısının, hem de ülkemizin enerji ithalatının azaltımı noktasında bu teknolojilerin konutlar için karlı bir yatırım aracı olarak öne çıkacağı görülmektedir.

\section{KAYNAKLAR}

[1] S. Uçar ve N. Kokulu, "Antalya Bölgesinde Yeni Tasarlanacak Binalarda Güneş Panellerinin Kullanım Potansiyelinin İncelenmesi," 4. Ulusal Yapı Kongresi ve Sergisi, Antalya, Türkiye, 2018, ss. 377-386.

[2] M. Anbarc1, Ö. Giran ve İ.H. Demir, "Uluslararası Yeşil Bina Sertifika Sistemleri ile Türkiye'deki Bina Enerji Verimliliği Uygulamas1," e-Journal of New World Sciences Academy, c. 7, s. 1, ss. 368-383, 2012, doi:10.12739/nwsaes.v7i1.5000066898

[3] ÇEDBİK. Yeşil Bina [Çevrimiçi]. Erişim Adresi: https://cedbik.org/tr/yesil-bina-7-pg Erişim Tarihi: 08.08.2020

[4] A. Seven, B. Topbaşlı ve B. Dursun, "Yeşil Yapı Konseptine Genel Bir Bakış," Ejovoc (Electronic Journal of Vocational Colleges), c. 4, s. 1, ss. 99-109. 2014, doi:10.17343/ejovoc.30362

[5] S.B. Erdede, B. Erdede ve S. Bektaş, "Kentsel Dönüşümde Yeşil Binaların Uygulanabilirliği," 5. Uzaktan Algllama-CBS Sempozyumu (UZAL-CBS 2014), İstanbul, Türkiye, 2014.

[6] B. Somalı ve E. Ilıcal1, "LEED ve Breeam Uluslararası Yeşil Bina Değerlendirme Sistemlerinin Değerlendirilmesi,” IX. Ulusal Tesisat Mühendisliği Kongresi, İzmir, Türkiye, ss. 1081-1088.

[7] B. Gültekin ve B. Bulut, "Yeşil Bina Sertifika Sistemleri: Türkiye için Bir Sistem Önerisi," 2nd International Sustainable Buildings Symposium, Ankara, Türkiye, 2015, ss. 813-823.

[8] C.H. Kılıç ve Ö. Güdük, "Yeşil Hastane Kavramı ve Türkiye'deki Son Kullanıcıların Beklentileri Üzerine Bir Hastane Örneği," Gümüşhane Üniversitesi Sağllk Bilimleri Dergisi, c. 7, s. 1, ss. 164-174, 2018.

[9] B. Köse-Mutlu, Z.O Arslanoğlu, B. Günaçtı, B. Say, F. Şahin, C. Yılmaz ve N. Yardımc1Tiryakioğlu, "Uluslararası Yeşil Bina Sertifika Sistemlerinin İncelenmesi ve Tasarlanan Ulusal Sertifika Sisteminin Kullanımı: Bir Kampüs Binası ile Vaka Çalışması," İklim Değişikliği ve Çevre, c. 4, s. 2, ss. 32-41, 2019.

[10] N.T. Bayazıt, B. Şan ve G. Ökten, "Yeşil Bina Sertifikasyonunda Akustik Performansın Değerlendirilmesi,” X. Ulusal Tesisat Mühendisliği Kongresi, İzmir, Türkiye, 2011, ss. 1567-1577.

[11] C. Yaman, "Siemens Gebze Tesisleri Yeşil Bina," IX. Ulusal Tesisat Mühendisliği Kongresi, İzmir, Türkiye, 2009, ss. 1091-1101.

[12] Çevre Dostu Yeşil Binalar Derneği. B.E.S.T- Konut Sertifikası [Çevrimiçi]. Erişim Adresi: https://cedbik.org/tr/b-e-s-t-konut-sertifikasi-12-pg Erişim Tarihi: 08.08.2020 
[13] S.B. Erdede, B. Erdede ve S. Bektaş, "Sürdürülebilir Yeşil Binalar ve Sertifika Sistemlerinin Değerlendirilmesi," 5. Uzaktan Algılama-CBS Sempozyumu (UZAL-CBS 2014), İstanbul, Türkiye, 2014.

[14] U. Bayar ve A.İ. Atılgan, "Yeşil Ev Tasarımı ve Enerji Analizi İçin Uygulama Örneği," Mühendis ve Makina, c. 56, s. 671, ss. 41-52, 2015.

[15] M. Yalılı Kılıç ve S. Yahşi, "Sürdürülebilir Enerji Kullanımının Yeşil Bir Ofise Uygulanması," Gümüşhane Üniversitesi Fen Bilimleri Enstitüsü Dergisi, c. 9, s. 3, ss. 557-568, 2019, doi: $10.17714 /$ gumusfenbil.512593

[16] Ö. Kayın, "Binalarda Enerji Modellemesi, Enerji Performans Analizi ve Yenilenebilir Enerji Kullanımının Çevre Dostu Yeşil Bina Uygulama Örneği Kapsamında Değerlendirilmesi,” Yüksek Lisans Tezi, Fen Bilimleri Enstitüsü, Namık Kemal Üniversitesi, Tekirdağ, Türkiye, 2019.

[17] Z. Mesci, "Otellerin Çevreci Uygulamalarının Değerlendirilmesi: Yeşil Yıldızlı Bir Otel İşletmesinde Örnek Olay Çalışması," Seyahat ve Otel İşletmeciliği Dergisi, c. 11, s. 1, ss. 90-102, 2014.

[18] S. Şenol, "Gayrimenkul Geliştirme Sürecinde Yeşil Binaların Sürdürülebilirlik Kriterleri Açısından İncelenmesi," Yüksek Lisans Tezi, Fen Bilimleri Enstitüsü, İstanbul Teknik Üniversitesi, İstanbul, Türkiye, 2009.

[19] İ. Erlalelitepe, G. Gökçen ve T. Kazanasmaz, "Yeşil Bina Sertifika Sistemlerinde Konut Tasarımının Önemi,” X. Ulusal Tesisat Mühendisliği Kongresi, Nisan 13-16, İzmir, Türkiye, 2011, ss. $1625-1633$

[20] U.S. Green Building Council. USGBC Project Profile [Çevrimiçi]. Erişim Adresi: http://www.usgbc.org/ShowFile.aspx?DocumentID=5106 Erişim Tarihi: 06.08.2020

[21] Ekoyapı. 10 Seçilmiş Örnek [Çevrimiçi]. Erişim Adresi: https://www.ekoyapidergisi.org/121210-secilmis-ornek.html Erişim Tarihi: 10.08.2020

[22] Yeşilist. Dünyadan 3 Yeşil Okul [Çevrimiçi]. Erişim Adresi: https://www.yesilist.com/dunyadan-3-yesil-okul/ Erişim Tarihi: 10.08.2020

[23] S. Sipahi ve F. Tavşan, "Otel Yapılarında Sürdürülebilir Yaklaşımlar ve Yeşil Bina Sertifikasyon Sistemleri," Nevşehir Bilim ve Teknoloji Dergisi, c. 8, ss. 20-30, 2019, doi: 10.17100/nevbiltek.572354

[24] Design Curial. Watg-Designed Bardessono Hotel Achieves Leed - Platinum [Çevrimiçi]. Erişim Adresi: http://www.designcurial.com/news/watg-designed-bardessono-hotel-achieves-leedplatinum Erişim Tarihi: 10.08.2020

[25] Y. Çilhoroz ve O. Işı1k, "Yeşil Hastane Sertifika Sistemleri," Sağlık Bilimleri ve Meslekleri Dergisi, c. 6, s. 1, ss. 161-169, 2019, doi: 10.17681/hsp.394880

[26] BREEAM. Best of Breeam- Today's Most Sustainable Buildings [Çevrimiçi]. Erişim Adresi: https://www.breeam.com/filelibrary/best_of_breeam_2013.pdf Erişim Tarihi: 07.08.2020

[27] M.M. Erdoğdu, C. Karaca, M.E. Çamlıbel, G. Alhanlıŏlu, Y. Akgün ve D. Uğurlu, "Enerji Tasarrufu Perspektifinden Çevre Dostu Sosyal Binalar ve Yaygınlaşmasına Hizmet Edebilecek Maliye Politikaları,”30. Türkiye Maliye Sempozyumu, Antalya, Türkiye. 2015.

[28] K. Kaya, “Türkiye'nin Yerli Konut Sertifikası ÇEDBİK-Konut'u Alan İlk Proje ANTTERAS," Yeşil Bina Dergisi, Y11:7, s. 37, ss.30-32. 2016. 
[29] F. Arslan ve M. Üzülmez, "Sürdürülebilir Üretimde Yeşil Binaların Rolü: Schneider Electric (Manisa) Örneği," II. Uluslararası Coğrafya Eğitim Kongresi, Eskişehir, Türkiye, 2019, ss. 1871-1878.

[30] Voltimum. LEED Sertifikalı Hilton Garden Inn'in Yeşil Özellikleri [Çevrimiçi]. Erişim Adresi: https://www.voltimum.com.tr/haberler/leed-sertifikali-hilton-garden-innin Erişim Tarihi: 06.08.2020

[31] F. Şahin ve P. Hocaoğlu, "Karma Yap1 Tasarımları ve Sürdürülebilir Mimarlık," $2^{\text {nd }}$ International Sustainable Buildings Symposium, Ankara, Türkiye, 2015, ss. 355-360.

[32] İ. Taşkıran, (Anadolu Ajansı). İstanbul Havalimanı Terminali Dünyanın En Büyük 'LEED Altın' Sertifikalı Binası Seçildi [Çevrimiçi]. Erişim Adresi: https://www.aa.com.tr/tr/turkiye/istanbulhavalimani-terminali-dunyanin-en-buyuk-leed-altin-sertifikali-binasi-secildi/1854885 Erişim Tarihi: 08.08.2020

[33] M. Güler, "Sürdürülebilir Tasarım Ölçütleri Bağlamında Yeşil Ofis Binalarının Analiz ve Karşılaştırılması," Yüksek Lisans Tezi, Sosyal Bilimler Enstitüsü, Selçuk Üniversitesi, Konya, Türkiye, 2016.

[34] TOKİ Haber. Türkiye Yeşil Bina Sayısında Avrupa Lideri [Çevrimiçi]. Erişim Adresi: https://www.tokihaber.com.tr/haberler/turkiye-yesil-bina-sayisinda-avrupa-lideri/ Erişim Tarihi: 07.08.2020

[35] F. Uyar. Elektrikli Aletler Kaç Watt Harcar? Tüketim Bilgileri [Çevrimiçi]. Erişim Adresi: http://www.enerjibes.com/elektrikli-aletler-kac-watt-harcar/ Erişim Tarihi: 06.08.2020

[36] Tekzen. Enerji Tasarruflu Ampul Fiyatı [Çevrimiçi]. Erişim Adresi: https://www.tekzen.com.tr/osram-spiral-dstar-mini-enerji-tasarruflu-ampul-23-watt-sari-isik-816891 Erişim Tarihi: 13.08.2020

[37] Doğa ile Barış Derneği. Su Tüketim Miktarları [Çevrimiçi]. Erişim Adresi: http://www.dogailebaris.org.tr/dib-den/su-tuketimi.htm Erişim Tarihi: 10.12.2017

[38] BUSKİ. Su Tarife Ücretleri Ne Kadar? [Çevrimiçi]. Erişim Adresi: https://www.buski.gov.tr/tr/abonerehberi/kategori_17 Erişim Tarihi:12.08.2020

[39] Limak Enerji Uludağ Elektrik Mesken Tip Ağustos Ayı Elektrik Fatura Dökümü, 2020.

[40] BURSAGAZ. Konut Fiyat Bilgileri [Çevrimiçi]. Erişim Adresi: https://www.bursagaz.com/konut-fiyat-bilgileri Erişim Tarihi: 12.08.2020

[41] S.B. Erdede ve S. Bektaş, "Ekolojik Açıdan Sürdürülebilir Taşınmaz Geliştirme ve Yeşil Bina Sertifika Sistemleri," Harita Teknolojileri Elektronik Dergisi, c. 6, s. 1, ss. 1-12, 2014.

[42] Anonim. Business Case for Green Building Report [Çevrimiçi]. Erişis Adresi: http://www.worldgbc.org/files/ BusinessCaseForGreenBuildingReport_web_pdf Erişim Tarihi: 15.03.2015

[43] L.O. Uğur ve N. Leblebici, "Yeşil Bina Sertifikalandırma Sistemlerinin İnşaat Maliyetleri ve Taşınmaz Değeri Üzerindeki Etkilerinin İncelenmesi," Düzce Üniversitesi Bilim ve Teknoloji Dergisi, c. 3, s. 2, ss. 544-576, 2015. 